\title{
Rewards of Parenting a Child with a Fetal Alcohol Spectrum Disorder
}

\author{
Jason D. Brown ${ }^{*}$, Susan Rodger, Natalie George, David St. Arnault and Jennifer Sintzel
}

Faculty of Education, University of Western Ontario, 1137 Western Road, London, N6G 1G7, Canada

\begin{abstract}
There is a considerable amount of research on the challenges associated with parenting children who have disabilities, and little that focuses on positive aspects. The purpose of the study was to describe the rewards of parents of children with a fetal alcohol spectrum disorder (FASD). Nineteen birth, foster or adoptive parents were asked to answer the following question: "What are the rewards of parenting a child with a FASD?" The data were analyzed using multidimensional scaling and cluster analysis. Four clusters resulted. Parents indicated that they saw the children's effort, growth, and accomplishment in a variety of domains as encouraging. Parents also reported feeling appreciated by the children. Results suggest that rewarding parenting experiences with children who have alcohol-related disabilities are multiple, diverse and, when compared to the literature, largely consistent. The results lend credibility to the existing literature on the rewards of parenting children with developmental disabilities, and FASD in particular.
\end{abstract}

Keywords: Fetal alcohol spectrum disorder, parenting, rewards.

Prenatal alcohol exposure on the developing fetus can result in multiple lifelong effects [1]. These effects vary with amount, duration and timing of alcohol consumption, the general health of the mother, as well as genetic factors [2-3]. Fetal alcohol syndrome (FAS) is characterized by craniofacial abnormalities, prenatal and/or postnatal growth restriction, and central nervous system impairment [4]. Fetal alcohol spectrum disorder (FASD) is an umbrella term that encompasses the complete spectrum of effects resulting from alcohol use during pregnancy $[2,5,6]$. FASD includes a range of diagnostic terms from FAS, to categories that include some of the features such as fetal alcohol effects, prenatal alcohol effects, partial fetal alcohol syndrome, alcohol related birth defects (ARBD) and alcohol related neurodevelopmental disorder [7-9].

A range of factors influences the ascertainment and diagnosis of FASD, and therefore its frequency has been difficult to determine [10]. Estimated prevalence of FAS in the United States ranges between 0.5 - 2 per 1000 live births and the rate of FASD between 9-10 per 1000 live births $[10,11]$. It has been estimated that the total of people with FASD in the United States exceeds 2.6 million [12]. Although Canadian studies have estimated the prevalence of FASD in small populations, there are currently no national data [5].

Children with an FASD diagnosis may experience medical complications related to hearing, speech and vision [3]. In addition, neurodevelopmental delays, most commonly in the forms of intellectual and attention-related disabilities [13-15], are present. In addition to these primary disabilities, children with FASD are also at high risk for the development of secondary disabilities. Secondary disabilities are those that a person is not born with and could potentially be ameliorated through intervention [16]. Streissguth and colleagues

\footnotetext{
*Address correspondence to this author at the Faculty of Education, University of Western Ontario, 1137 Western Road, London, N6G 1G7, Canada; Tel: 519-661-2111, Ext. 88617; Fax: 519-661-3833;

E-mail: jbrow97@uwo.ca
}

[16] found that across 415 individuals with FASD, 94\% had mental health problems, $45 \%$ engaged in inappropriate and repeated sexual behaviour, $43 \%$ experienced disrupted school experience (i.e. were suspended, expelled or dropped out of school) and $42 \%$ engaged in illegal behaviour that put them into contact with the justice system. It was noted that a stable, nurturing family was the most significant factor in the prevention of secondary disabilities [17]. The combined effect of an early diagnosis and a stable home environment reduced the likelihood of secondary disabilities by as much as 2 to 4 times [17].

While research has shown that family environment plays a significant and potentially protective role in the development of secondary disabilities, little research to date has focused on the experiences of parents. Indeed, parents of children with disabilities report that professionals often assume the role of 'expert' with respect to their children, neglecting and even over-riding the expertise of the parents [18]. The research that has been done has focused less attention on positive parenting experiences, and tends to emphasize the challenges of parenting children with alcohol-related diagnoses. The purpose of the study was to describe the rewards of parenting children affected by FASD. Parents in a centralCanadian province were asked to respond to the question "What are the rewards of parenting a child with a FASD?" Parents' responses are compared to the available literature on positive aspects of parenting children with developmental disabilities, as well as the few references available on parenting children that have a diagnosed disability in the fetal alcohol spectrum.

\section{LITERATURE REVIEW}

While multiple studies have documented elevated stress among parents of children with disabilities [19-24], parents also report a high level of satisfaction with their role [25] and when asked, focus more on the benefits of caregiving [26]. 
A range of parenting challenges have been described in the literature. Parents of children with disabilities in general [27] and alcohol-related disabilities in particular [28] have described the experience as more difficult and rewarding than anticipated. Particular concerns parents of alcoholaffected children expressed included those for the present as well as the future. They were reinforced by observations of their child's particular difficulties with memory and appreciation of consequences [29]. They worried about social relationships, in particular, the potential for aggression by their child as well as potential victimization of their child.

Studies on positive caregiver experiences of children with developmental disabilities indicated several types of rewards including: feelings of general positivity and happiness, heightened perceptions of parenting competency, increased closeness in the family, and experiences of personal growth. In addition, research on parenting children with alcohol-related disabilities suggested that parents experienced rewards in helping their children increase their strengths and potential, and recognizing their children's persistent efforts to succeed. Recent literature on concept mapping, the method employed in this study, is briefly reviewed.

\section{General Positivity}

Parents described feelings of happiness when thinking about their children [30] and derived deal of pleasure themselves from seeing their children, with disabilities, be happy [26]. Parents have also described a sense of purpose and fulfillment, as well as pride in their childrens' efforts and achievements [31]. It was especially rewarding for parents to see their children achieve or succeed at something they were not expected to be capable of [32].

Parents of children with disabilities rated their parenting experience as positively as parents of children without disabilities. For example, parents of children with Down Syndrome felt equally rewarded compared to parents of children without Down Syndrome [33]. In addition, parents viewed their children with Down Syndrome as happier and as a greater source of positive reinforcement to them [34]. These same parents reported less stress and more child-related rewards than parents of children with other disabilities [33]. Mothers parenting teenagers with disabilities were more positive about their children than mothers of teenagers without disabilities [35]. Parents who perceived more positive impacts of parenting children with disabilities also reported less stress and more gratification [36-37].

\section{Parenting Competence}

High ratings of parenting confidence among parents of children with disabilities have been found [30]. This sense of confidence included the ability to give good care to their children, ensure that the children's needs were well attended to [26] as well as promote a sense of self-determination [38]. For example, mothers of children with Down syndrome rated their child rearing competence in infancy higher than did mothers of children without disabilities [25]. It should be noted that parents who reported feeling competent also reported taking pride in their abilities [39].

\section{Family Closeness}

In some families unity has been enhanced by the experience of caring for a member with a disability. Parents have reported that they felt more tightly knit, and closer to their children [30-31]. Families felt that they grew stronger because of the shared experience of addressing inherent challenges, such as the pain of dealing with negative perceptions of outsiders [32]. Caregivers have also reported gaining new networks in their communities, improved support, and increased communication and closeness within the family [31].

\section{Personal Growth}

Experiences of personal growth were among the most commonly reported and strongly emphasized rewards reported by parents of children with disabilities. Indeed, an analysis of books written by parents of children with disabilities revealed that the majority of the 60 authors felt their lives had increased meaning and enrichment as a result of their experiences [40]. Parents have described the experience of caring for a child with a disability has having made them less selfish, broadening their interests, providing a sense of purpose, and testing their abilities [26]. In addition, many parents report experiencing an increased sense of compassion [30], increased tolerance and understanding, feelings of personal strength, and ability to challenge people in positions of authority on behalf of their family and children [32].

Even in the face of challenges parents have focused on the positive outcomes and rewards of parenting a child with a disability. Parents who experienced a particularly stressful event reported a positive outcome or benefit including: increased assertiveness and determination, a new outlook and increased understanding, and working through feelings and emotions [31]. In relation to ongoing demands of care giving, parents reported positive aspects including: a new outlook, greater acceptance, increased understanding of others, tolerance, patience, and appreciation of life, as well as development of positive personal characteristics and changed focus of priorities.

\section{Parenting Children with an FASD}

Studies describing caregiver experiences with children who have an alcohol-related disability focused on evaluating methods for fostering children's' growth and development and increasing caregiver efficacy. However, these studies suggested that through efforts to support and advocate on behalf of their children, caregivers experienced rewards in helping their children recognize their own efforts to succeed, enhance their strengths, and realize their potential.

The theory of the zone of proximal development indicates the difference between what a child can do when acting alone and what he or she can do when acting with the guidance of a caregiver [41]. By providing structure, consistency, and support, caregivers effectively maximize their children's strengths and potential [29, 42-44]. These findings suggest that when caregivers successfully meet their children's particular needs, they may experience the rewards of facilitating their children's development. 
Caregiver support additionally impacts children's persistent efforts to experience academic growth and success. In a study of adolescents diagnosed with FASD it was revealed that all the participants acknowledged their parents' support as an important factor in persistence at school [42]. Caregivers also recognized how their supportive efforts influenced their children's persistence. By advocating on their children's behalf within school systems, and having expectations that their children complete their education, caregivers have had a positive impact on their children's school achievements [42]. Through these advocacy efforts and realistic expectations caregivers experience the rewards of recognizing and appreciating their children's strengths and potential.

\section{Concept Mapping}

Concept mapping is a quantitative approach to the analysis of qualitative data. Multiple participants generate of responses to a question as well as organize all responses into concepts. Only unique responses are used in the analysis. Participants are provided with a full set of all responses made to the question and asked to group them together. These independent groupings are analyzed statistically, to identify common themes. What distinguishes concept mapping from other qualitative methods is the involvement of multiple participants in the interpretation of all responses. For example, the Delphi method is a commonly utilized qualitative approach to represent the views of experts. In contrast to concept mapping, Delphi is future-oriented, "reasons" are given for responses, and there are several rounds used to refine responses. Concept mapping is not limited to future orientation, no "reasons" for responding in a particular way are required of participants, and there is only one round of responding. Both are qualitative methods and utilize structured interviews, but the analysis and interpretation are quite different.

The concept mapping approach has been used in program development, implementation and evaluation studies appearing in the health, social welfare and psychology literatures. Development of nutrition programs for college students [45], implementation of a novel mental health care case management model [46], as well as the evaluation of a drop-in centre for youth [47] and addiction treatment programs [48] have been described using this approach. Intervention strategy development targeting medication and health treatment adherence [49-50] as well as program participation among at-risk youth and adults with health conditions have also been studied [51-53]. Theory development [54-56] and operationalization of constructs for research purposes such as motives among youth for school leaving [57], stress and coping activities among homeless individuals [58] individuals with diabetes [59] and characteristics of an effective counselor [60] are also examples of applications of this method.

Like any method, concept mapping is subject to researcher bias and ideological preoccupation [61]. The value of knowledge co-construction between participant and researcher is fundamental to the authors of the study, and led to the selection of concept mapping as an appropriate method. A main advantage of the method is that participants are directly involved in the analysis of qualitative data. The researchers' contributions are in the selection of the question and decision about final number of concepts. Our previous work in the area of disabilities led us to the decision that a focus on positive aspects of parenting was important to study, as the vast majority of family research on this topic is deficit-oriented. Our interpretation of the concepts that resulted from the study was guided by the belief that families are the experts on their experiences, and that they do what is most adaptive for them under their particular circumstances. We chose therefore, to interpret the results as adaptive responses to situations.

\section{METHOD}

There were five steps to the concept mapping method employed in the study [62]. First, participants were recruited and asked to respond to a question. Second, redundant responses were removed and those remaining were edited for clarity. In the third step, a complete set of responses to the question by all participants was provided to each who was asked to group them into concepts. Fourth, statistical analysis was employed on the groupings provided by participants, which included multidimensional scaling and cluster analysis. A decision was made by researchers about the optimal number of concepts based on the analysis. Finally, the concepts were given descriptive labels by researchers, based on the responses contained within each.

\section{Participants}

The study was advertised in a province-wide family association newsletter for parents of children with disabilities. Posters were also placed within an urban hospital clinic specializing in alcohol-related diagnosis. Interested parents were instructed to contact the researchers directly by telephone. Each caller was informed about the purpose of the study as well as what participation would include, right to withdraw at any time as well as confidentiality and anonymity. Participants who provided verbal consent to participate were asked the question: "what are the rewards of parenting a child with a FASD?". Interviews were conducted over the telephone, and the interviewer took notes. Data were collected over a period of 3 months.

Data collection continued until saturation was reached. In this study, it was predetermined that saturation would occur after three consecutive interviews during which no unique responses were obtained. Saturation was reached after interviewing 19 participants. Each of the 19 parents from 14 families who contacted the researchers to find out more about the study, agreed to participate. The majority (12 out of 19) were female. Most (16 out of 19) had fostered a child with a medical diagnosis in the fetal alcohol spectrum, and less than half were adoptive (8 out of 19) or birth (2 out of 19) parents. It should be noted that the same participant could be a birth, adoptive and adoptive foster parent to different children in her or his home at the same time and therefore, the total parenting category frequency total was greater than the number of participants. Participants who had experience in different parenting roles were asked to respond to the question from each of those roles.

All participants resided in a central Canadian province. Most (14 out of the 19) resided within the largest urban centre of the province with a population of approximately 600,000 , while the other 5 were located in nearby rural communities. At the time they were parenting a total of 25 
children aged 2-12 years who had a FASD. The average age of the children with FASD was 8.4 years. The diagnoses, according to parental report, included Fetal Alcohol Syndrome (14 children), Fetal Alcohol Effect (6 children), partial Fetal Alcohol Syndrome (3 children), and Alcohol related Neurodevelopmental Disorder (2 children).

\section{Responses}

A total of 53 responses were made to the question. A psychologist, family life specialist and elementary school teacher independently reviewed all responses to identify any that were redundant or unclear. The psychologist and elementary school teacher had professional experience with families affected by FASD. When two reviewers identified a response in need of editing or that could be removed, the reviewers decided together how to make the change. Editing for clarity and essential meaning was followed by the removal of any remaining responses that were redundant. In this study, redundancy occurred when two reviewers independently identified a particular response as meaning essentially the same as another response. When this occurred, one of the redundant responses was removed from the analysis. Following this procedure, 36 responses remained in the analysis.

\section{Grouping}

All participants were asked during the initial interview if they were interested in participating in the grouping task at a later time, and all consented. Each was again contacted by telephone, provided with a brief description of the grouping task, and mailed out a package of information and materials. Each was instructed to read the 36 responses and group them together in a way that made sense to her or him. Ten participants returned their grouping data.

\section{Analysis}

The Concept System [63] was used to perform the multidimensional scaling and cluster analyses that organized the grouping data in order to identify underlying concepts and presented these results visually on a concept map.

Multidimensional scaling [64] placed the responses on a 2-dimensional space called a point map where distances between responses indicated the frequency with which they were grouped together by participants. Responses closer together on the map were grouped together more often than responses far apart. A bridging index was calculated for each response. It was a value between 0 and 1 that indicated the extent to which a response was grouped together with others in other areas of the map. A low bridging index value (less than 0.25 ) indicated that the response was not often grouped together with responses in areas further from it on the map, while a high bridging index value (greater than 0.75 ) indicated that the response was often grouped together with responses in areas further from it on the map.

Cluster analysis [65-67] placed the responses into clusters representing higher-level aggregates. In this analysis, each response starts out as its own cluster. In each step of the analysis, two clusters were combined. The analysis continued until all responses were in one cluster. An average bridging index was calculated for each cluster. Lower cluster averages (below 0.25) indicate greater within-cluster consis- tency, and higher averages (above 0.75) indicate greater between cluster-consistency. Researchers examined the default cluster solution (4 clusters), as well as solutions with more (5, 6 , and 7 clusters) and less (3, and 2 clusters) before determining that the four-cluster solution represented the data best. The decision was based on conceptual and statistical fit. Both conceptual similarity between responses in the cluster and average bridging index were used to determine the most appropriate number of concepts. Conceptual overlap of individual statements between clusters was considered as well, but secondary to within-cluster similarities.

\section{Labels}

At the time participants were asked to group responses together, they were also asked to provide a label for each of their groupings. When assigning labels to the clusters in the four-cluster solution, the researchers used these suggestions. When the labels from participants corresponded to the responses within the clusters, they were used.

\section{RESULTS}

The resulting concept map appears in Fig. (1). Each number, identified by point on the map, corresponds to a numbered response in Table 1. Parents grouped the 36 responses into four concepts. The first concept focused on being aware of the children's efforts to succeed, and the second on the appreciation they received from the children. The third concept described the changes in self-confidence among the children, and the fourth emphasized the children's accomplishments.

\section{Concept One: Child's Positive Effort}

In this concept, responses focused on the strengths their children had that through effort and patience led them to success with difficult tasks. Parents talked about their child's "persistence", and that it earned their child "recognition for an accomplishment". The strengths that the children brought to their activities, such as "her sense of humor" and being "able to forget bad things", that "help us out" at home, made it possible for more "one-on-one time" with the children. Parents also noted that these efforts by their children with alcohol-related disabilities were no different than the efforts they saw from their children who did not have such a diagnosis: "rewards no different than with other kids".

\section{Concept Two: Being Appreciated}

Statements in this cluster focused on being appreciated as a parent. Participants indicated that they felt valued when a child "let me care" enough to form an "attachment to me". They observed their children being "comfortable living here". Parents found it rewarding when a child said "thanks" as well as when "he says that he loves me". It was also noted that parenting a child with an alcohol-related disability was "as rewarding as parenting any child".

\section{Concept Three: Gain in Self-Confidence}

In this cluster, statements concerned increasing confidence in abilities they saw among their children. Parents described seeing the children "enjoy something that used to be difficult", such as to "achieve in school". They noted that it was rewarding to see a child "finding something he excels at", feeling "proud of herself" and hearing that he "tells oth- 
ers about his accomplishments". Just "hearing him laugh", knowing that a child is "happy" and "feels safe" were rewarding experiences. Observing their children "gaining independence" was also important.

Table 1. Concept Items and Bridging Values for Concept Map

\begin{tabular}{|c|c|}
\hline Cluster and Statement & Bridging Index \\
\hline $\begin{array}{l}\text { Child's Positive Effort } \\
\text { 31. recognition for an accomplishment } \\
\text { 12. persistence } \\
\text { 9. her sense of humor } \\
\text { 1. able to forget bad things } \\
\text { 24. one-on-one time } \\
\text { 17. rewards no different than with other kids } \\
\text { 26. help us out }\end{array}$ & $\begin{array}{l}0.61 \\
0.13 \\
0.36 \\
0.42 \\
0.72 \\
0.75 \\
0.90 \\
1.00\end{array}$ \\
\hline $\begin{array}{l}\text { Being Appreciated } \\
2 . \quad \text { as rewarding as parenting any child } \\
\text { 10. attachment to me } \\
\text { 13. comfortable living here } \\
\text { 25. let me care } \\
\text { 6. he says that he loves me } \\
\text { 23. thanks }\end{array}$ & $\begin{array}{l}0.30 \\
0.21 \\
0.22 \\
0.31 \\
0.34 \\
0.34 \\
0.37\end{array}$ \\
\hline $\begin{array}{l}\text { Gain in Self-Confidence } \\
\text { 20. happy } \\
\text { 30. proud of herself } \\
\text { 7. hearing him laugh } \\
\text { 33. tells others about his accomplishments } \\
\text { 14. feels safe } \\
\text { 21. gaining independence } \\
\text { 19. enjoy something that used to be difficult } \\
\text { 3. finding something he excels at } \\
\text { 18. achieve in school }\end{array}$ & $\begin{array}{l}0.21 \\
0.11 \\
0.11 \\
0.17 \\
0.19 \\
0.20 \\
0.23 \\
0.24 \\
0.34 \\
0.35\end{array}$ \\
\hline $\begin{array}{l}\text { Child's Accomplishments } \\
\text { 22. creativity } \\
\text { 32. organizes himself } \\
\text { 16. reaching milestones } \\
\text { 5. he remembers something he worked on } \\
\text { 4. he articulates what he is thinking } \\
\text { 35. exceeds expectations } \\
\text { 29. goes all out on something constructive } \\
\text { 36. something gets through } \\
\text { 8. her eagerness to learn } \\
\text { 15. has made a change } \\
\text { 28. follows through } \\
\text { 34. does her homework } \\
\text { 27. grow up } \\
\text { 11. attention to detail }\end{array}$ & $\begin{array}{l}0.25 \\
0.00 \\
0.00 \\
0.07 \\
0.07 \\
0.09 \\
0.12 \\
0.13 \\
0.14 \\
0.24 \\
0.30 \\
0.36 \\
0.43 \\
0.64\end{array}$ \\
\hline
\end{tabular}

\section{Concept Four: Child's Accomplishments}

In this concept, the statements focused on the changes that their children made which led to more opportunities in their lives. With "creativity" and "attention to detail", a child who "organizes himself", "follows through", for example "does her homework", and "goes all out on something con- structive", was "reaching milestones" and "exceeds expectations". Parents talked about noticing when a child "has made a change" as s/he "grow(s) up", and demonstrated it when "he articulates what he is thinking" or "he remembers something he worked on". It was rewarding for parents to observe "her eagerness to learn" and noticed when "something gets through".

\section{DISCUSSION}

The purpose of the study was to describe the rewards of parents with children who have a diagnosis in the FASD spectrum, from their perspective. A comparison of the needs of parents identified in the current developmental disabilities literature in general, as well as the FASD literature in particular, and those identified by parents themselves may lend credibility to the existing literature and assist in the identification of gaps in the literature on factors that help parents to provide stable and nurturing environments for children with FASD. Results of the concept mapping process are described and compared to the available literature. Similarities and differences are noted.

\section{Concept One: Child's Positive Effort}

While there is a great deal of support in the literature for enhanced sense of confidence among parents of children with disabilities who see their role in the child's success [25, $29-31,39,43,44]$ there is much less attention given in the literature to the privilege of being part of the effort that children put into doing something difficult for which parents may not be able to take credit. Children benefit from stable and nurturing family experiences, but these benefits may be qualitatively different than the kind of support they receive. Using the support they receive from their families as a springboard, parents report that the children develop qualities that move their participation in the enhancement of family life from that of being a recipient of support to being an active contributor. Examples of these qualities in a child that are well in excess of what they get from their parents and families for support include a sense of humour and a positive outlook.

\section{Concept Two: Being Appreciated}

There are several references in the literature related to the sense of personal fulfillment experienced by parents of children with disabilities $[30,34,39,42]$. The data from this study imply that the children, not parents, determined the extent to which caregivers were responded to positively, and in doing so lead the efforts by parents to respond effectively to them. It is suggested that much of the research on parenting appreciation and fulfillment is based on realizing the outcomes of parent-to-child transmission of values and practices, while the participants in this study suggest that the child-to-parent transmission of values and practices is fundamental.

\section{Concept Three: Gain in Self-Confidence}

The literature on overcoming barriers, both internal to the child [31] and family [16], as well as external within the school and other community settings has been well described [e.g. 32]. Within the literature, parents describe how these experiences change them and their confidence [31], for example, when dealing with individuals in positions of author- 


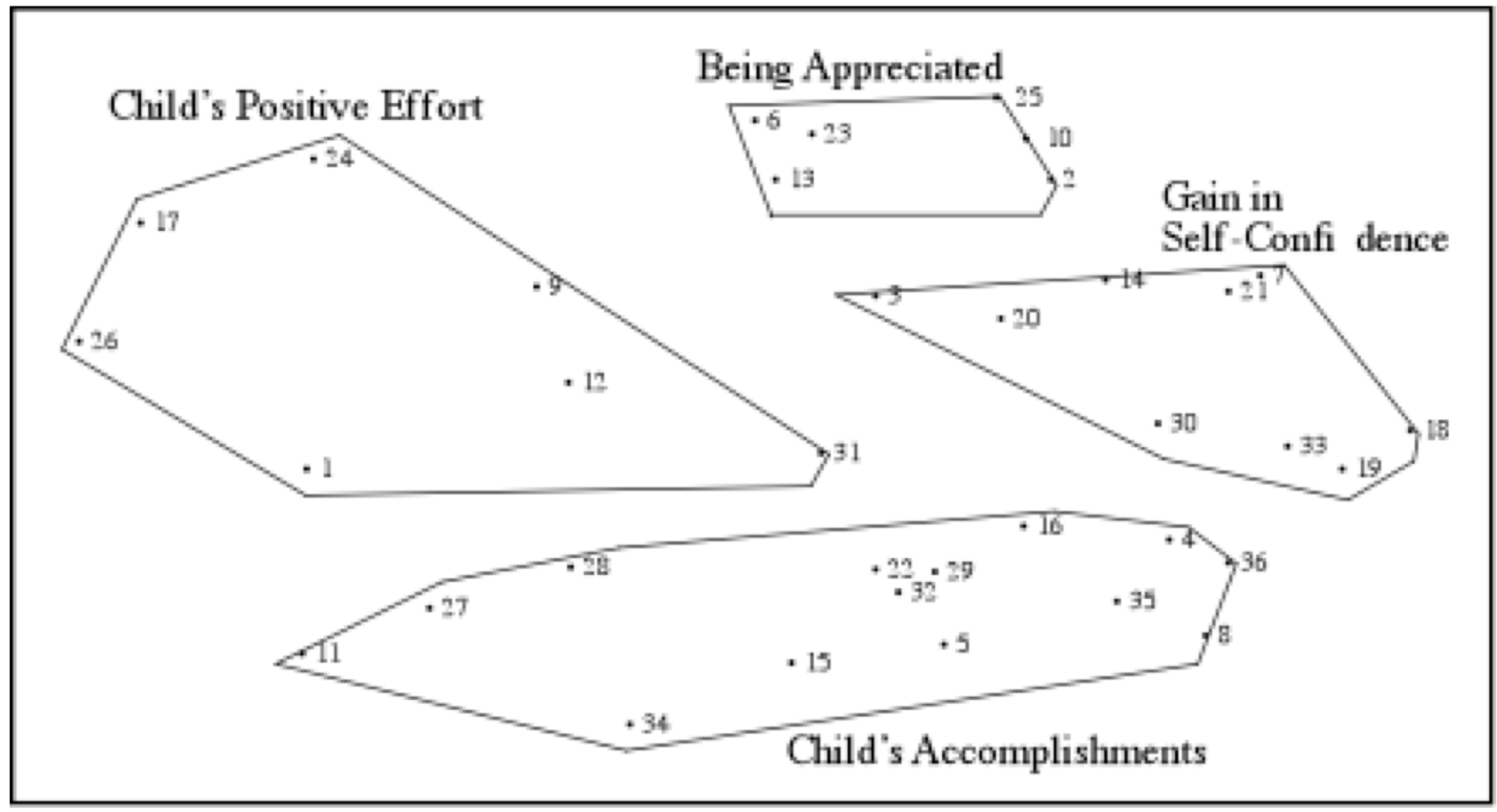

Fig. (1). Concept map of 36 statements.

ity [32], while participants in the study emphasized the benefits to the children. Hastings and Taunt [25], in their review of the positive impacts of parenting children with disabilities, note that parents report increases in confidence, ability as advocates and positive self-views.

\section{Concept Four: Child's Accomplishments}

There were references in the literature about positive aspects of parenting children with disabilities that focused on the child's abilities to succeed. Parents of children with disabilities have described a great sense of personal pride in their children's efforts and achievements [31], and happiness for the children, when they accomplished something new or challenging [33].

\section{CONCLUSION}

There were many similarities between the experiences of participants in this study and the available literature. Parents in the study and those surveyed in previous studies indicated that it was as rewarding to care for a child with a disability as it was to care for a child without a disability [25]. Parenting competence, and feeling more confident in their abilities when it came to caring for children with disabilities, as well as those with alcohol-related disabilities in particular [29, 43, 44] was noted by participants and consistent with the literature. Participants in the study also reported a great sense of personal fulfillment from appreciated by the children, and this reward was also noted in the literature [34, 39, 42]. Another consistency between the literature and the experiences of participants in this study concerned the reward of overcoming barriers that children with disabilities face in their schools and communities [3, 16, 32]. Finally, both participants in the study and the literature described the positive experience of seeing their children succeed at something that may have been difficult or challenging $[31,33]$.
There were also some differences between the experiences of participants in the study and what had been reported in the literature. There were several references in the literature to the positive family effects of parenting children with disabilities, in terms of bringing families closer together and feeling closer as a unit $[30,31]$. One possible reason for this difference is the nature and duration of family relationships between the studies. In the present study, most participants were foster and adoptive parents, and so may not have been parenting the child (ren) in the same way, or for as long as birth parents who are highly represented in previous studies.

The other differences between the experiences of participants in this study and the results of previous research were subtle, but we believe, important to highlight because of the implications for future research in this area. Parents in our study described the child as the focus of the family, in terms of leadership and location of rewards to them as caregivers. It was suggested by parents in the study that they received rewards from the children in excess of what they gave, and that caring for them was a privilege. Parents also reported that the children led the family and their care giving in way that was responsive and helpful. It was suggested that the real "experts" in these homes, according to the parents we spoke with, were the kids, and not themselves.

\section{IMPLICATIONS}

The orientation to parenting described by participants in this study is child-oriented to an extent not captured in existing research in this area. The emphasis on the child as expert on her or his needs, and the implied care-giving role of meeting those needs implies a hierarchy that is different than how parenting is often described in Western culture. The children, according to caregivers, were placed at the centre of the family, and to a large extent influenced what and how care giving happened. It is difficult to determine if this result is a 
function of the: 1) types of families who participated in this study, who self-selected, were foster or adoptive parents, had experience caring for children with disabilities and felt successful in those endeavors, 2) type of study that was qualitative, held over the telephone at a convenient time for parents, included no follow up or observational data, or 3) the children they parented who were younger, well-adjusted, successful, and supported. However, future research employing different methods, with different families, and different children may be helpful to increase understanding of this approach to parenting and its relationship to a range of child, parent, and family outcomes.

The absence of family-wide benefits noted in the literature but not reported in the experiences of participants in this study suggests that the level of "family" reward was not as salient as other rewards, if it existed at all, among these parents. Parents in this study focused on the child and her or his impact on their parenting, but not on the family as a whole. It may be useful for future research to explore the place of "family" in the lives of the children with disabilities, in terms of the roles, functions, and impact of a range of family compositions and relationships.

Participants appreciated the opportunity to participate, and identified their children as the experts on what they needed to be healthy and happy. It would follow that an appropriate clinical orientation for working with families would strengths-based, emphasize capacities and gifts, and focus on enhancing well being. Because participants situated the expertise on their needs and resources within their families, it would be appropriate to follow the direction of the family, and children in particular, as opposed to focusing solely on the professional's perception of the family's experiences.

\section{Limitations}

There are several limitations inherent in the methods employed for this study. Participants selected themselves for involvement by responding to advertisements, and therefore may be different than those who did not participate. As well, there was no sampling frame from which participants were selected, so the generalizability of these results is limited. The degree of parenting satisfaction detected by the study cannot be considered specific to parents of children with a FASD. Due to small sample size, comparisons between different participants (e.g. those from lower versus higher income categories, those with more or fewer children) would yield numbers too small to make meaningful comparisons. The concept mapping method employed did not take into account frequencies of responses. The results do not indicate relative importance of responses of concepts. Finally, the consistency of the concept analysis was not supported through the use of a second grouping task among other participants, perhaps the 9 interview participants who did not participate in the grouping task, who may have organized the responses differently than the 10 who did group responses.

\section{ACKNOWLEDGEMENTS}

The authors would like to acknowledge the financial support of this research through a grant from the Manitoba Institute of Child Health. We would also like to thank L.
Bednar and S. Reiser for their assistance with the data collection and analysis.

\section{REFERENCES}

[1] Green, RF, Stoler, JM. Alcohol dehydrogenase 1B genotype and fetal alcohol syndrome: A huge mini-review. Am J Obstet Gynecol 2007; 197: 12-25.

[2] Jacobson SW, Carr LG, Croxford J, Sokol R J, Li T, Jacobson JL. Protective effects of the alcohol dehydrogenase-ADH1B allele in children exposed to alcohol during pregnancy. J Pediatr 2006; 148 : 30-7.

[3] Roberts G, Nanson J. Best practices: Fetal alcohol syndrome/fetal alcohol effects and the other substance use during pregnancy. Ottawa, Canada: Health Canada 2001.

[4] Jones KL, Smith DW. Recognition of the fetal alcohol syndrome in early infancy. Lancet 1973; 2: 999-1001.

[5] Chudley AE, Conry J, Cook JL, Loock C, Rosales T, LeBlanc N. Fetal alcohol spectrum disorder: Canadian guidelines for diagnosis. Can Med Assoc J 2005; 172: S1-21.

[6] Streissguth AP, O'Malley K. Neuropsychiatric implications and long-term consequences of fetal alcohol spectrum disorders. Semin Clin Neuropsychiatry 2000; 5: 177-90.

[7] Connor PD, Sampson PD, Streissguth AP, Bookstein FL, Barr HM. Effects of prenatal alcohol exposure on fine motor coordination and balance: A study of two adult samples. Neuropsychologia 2006; 44: 744-51.

[8] Manning MA, Hoyme HE. Fetal alcohol spectrum disorders: A practical clinical approach to diagnosis. Neurosci Biobehav Rev 2007; 31: 230-8.

[9] Sokol RJ, Delaney-Black V, Nordstrom B. Fetal alcohol spectrum disorder. JAMA 2003; 290: 2996-9.

[10] May PA, Gossage JP. Estimating the prevalence of fetal alcohol syndrome: A summary. Alcohol Res Health 2001; 25: 159-67.

[11] Sampson PD, Streissguth AP, Bookstein FL, et al. Incidence of fetal alcohol syndrome and prevalence of alcohol-related neurodevelopmental disorder. Teratology 1997; 56: 317-26.

[12] Burd L, Cotsonas-Hassler TM, Martsolf JT, Kerbeshian J. Recognition and management of fetal alcohol syndrome. Neurotoxicol Teratol 2003; 25(6): 681-8.

[13] Clarren SK, Smith DW. The fetal alcohol syndrome. N Engl J Med 1978; 298(19): 1063-7.

[14] Nicols GA. Fetal alcohol syndrome: Implications for psychologists. Clin Psychol Rev 1994; 14(2): 91-111.

[15] Steinhausen H, Spohr H. Long-term outcome of children with fetal alcohol syndrome: Psychopathology, behavior, and intelligence. Alcohol Clin Exp Res 1988; 22(2): 334-8.

[16] Streissguth A, Barr H, Kogan J, Bookstein F. Primary and secondary disabilities in fetal alcohol syndrome. Seattle, WA, US: University of Washington Press 1997.

[17] Streissguth AP, Bookstein FL, Barr HM, et al. Risk factors for adverse life outcomes in fetal alcohol syndrome and fetal alcohol effects. J Dev Behav Pediatr 2004; 25(4): 228-38.

[18] Case S. Refocusing on the parent: What are the social issues of concern for parents with disabled children? Disabil Soc 2000; 15(2): 271-93.

[19] Bradley RH, Rock SL, Whiteside L, Caldwell BM, Brisby J. Dimensions of parenting in families having children with disabilities. Exceptionality 1991; 2: 41-61.

[20] Dumas JE, Wolff LC, Fisman SN, Culligan A. Parenting stress, child behavior problems, and dysphoria in parents of children with autism, Down syndrome, behavior disorders, and normal development. Exceptionality 1991; 2: 97-110.

[21] Hendriks A, DeMoor J, Oud J, Savelberg M. Perceived changes in well-being of parents with a child in a therapeutic toddler class. Res Dev Disabil 2000; 21: 455-68.

[22] McKinney B, Peterson R. Predictors of stress in parents of developmentally disabled children. J Pediatr Psychol 1987; 12: 133-50.

[23] Rodrigue J, Morgan SB, Geffken G. Families of autistic children: Psychological functioning of mothers. J Clin Child Psychol; 1990; 19: 371-9.

[24] Smith TB, Oliver MN, Innocenti MS. Parenting stress in families of children with disabilities. Am J Orthopsychiatry 2001; 71: 25761. 
[25] Hastings RP, Taunt HM. Positive perceptions in families of children with developmental disabilities. Am J Ment Retard 2002; 107(2): 116-27.

[26] Grant G, Ramcharan P, McGrath M, Nolan M, Keady J. Rewards and gratifications among family caregivers: Towards a refined model of caring and coping. J Intellect Disabil Res 1998 43(1): 5871.

[27] Spratt E, Saylor C, Macias M. Assessing parenting stress in multiple samples of children with special needs (CSN). Fam Syst Health 2007; 25(4): 435-49.

[28] McCarty C, Waterman J, Burge D, Edelstein SB. Experiences, concerns, and service needs of families adopting children with prenatal substance exposure: Summary and recommendations. Child Welfare 1999; 78(5): 561-77.

[29] Gardner J. Living with a child with Fetal Alcohol Syndrome, MCN Am J Matern Child Nurs 2000; 25: 252-7.

[30] Sandler AG, Mistretta, LA. Positive adaptation in parents of adults with disabilities. Educ Train Ment Retard Dev Disabil 1998; 33. 123-30.

[31] Rapanaro C, Bartu A, Lee AH. Perceived benefits and negative impact of challenges encountered in caring for young adults with intellectual disabilities in the transition to adulthood. J Appl Res Intellect Disabil 2008; 21: 34-47.

[32] Stainton T, Besser H. The positive impact of children with an intellectual disability on the family. J Intellect Dev Disabil 1998; 23(1): 57-70.

[33] Hodapp RM, Ly TM, Fidler DJ, Ricci LA. Less stress, more rewarding: Parenting children with Down syndrome. Parent Sci Pract 2001; 1(4): 317-37.

[34] Noh S, Dumas J, Wolf C, Fisman S. Delineating Sources of Stress in Parents of Exceptional Children. Fam Relat 1989; 38(4): 456-61.

[35] Lehman J, Roberto K. Comparison of factors influencing mothers' perceptions about the future of their adolescent children with and without disabilities. Ment Retard 1996; 34: 27-8.

[36] Blacher J, Baker BL. Positive impact of intellectual disability on families. Am J Ment Retard 2007; 112(5): 330-48.

[37] Schwartz C. Parents of children with chronic disabilities: The gratification of caregiving. Fam Soc 2003; 84(4): 576-84.

[38] Field S, Hoffman A. The importance of family involvement for promoting self-determination in adolescents with autism and other developmental disabilities. Focus Autism Other Dev Disabl 1999; 14(1): 36-42.

[39] Haldy M, Hanzlik J. A comparison of perceived competence in child-rearing between mothers of children with down syndrome and mothers of children without delays. Educ Train Ment Retard 1990; 25(2): 132-41.

[40] Mullins JB. Authentic voices form parents of exceptional children. Fam Relat 1987; 36: 30-3.

[41] Vygotsky L. Thought and language. Cambridge, MA: MIT Press 1967.

[42] Duquette C, Stodel E, Fullarton S, Hagglund K. Persistence in high school: Experiences of adolescents and young adults with fetal alcohol spectrum disorder. J Intellect Dev Disabil 2006; 34: 219-31.

[43] Ryan S, Ferguson D. One, yet under, the radar: Students with fetal alcohol syndrome disorder. Except Child 2006; 72: 363-79.

[44] Timler G, Olswang L. Variable structure/variable performance: Parent and teacher perspectives on a school-age child with FAS. Journal of Positive Behavior Interventions 2001; 3: 48-56.

[45] Cousineau TM, Goldstein M, Franko D. A collaborative approach to nutrition education for college students. J Am Coll Health 2004; 53(2): 79-84.

[46] Cousins JB, Aubry TD, Fowler HS, Smith M. Using key component profiles for the evaluation of program implementation in in- tensive mental health case management. Eval Program Plann 2004; 27(1): 1-23.

[47] Mercier C, Piat M, Peladeau N, Dagenais C. An application of theory-driven evaluation to a drop-in youth center. Eval Rev 2000 ; 24(1): 73-91.

[48] Nabitz U, van den Brink W, Walburg J. A quality framework for addiction treatment programs. Addict Behav 2005; 30(6): 1254-60.

[49] Gilbert DJ, Abel E, Stewart NF, Zilberman M. More than drugs: Voices of HIV-seropositive individuals with a history of substance use reveal a range of adherence factors. J AIDS HIV 2007; 6(1-2): 161-79.

[50] Kikkert MJ, Schene AH, Koeter M, et al. Medication adherence in Schizophrenia: Exploring patients', carers' and professionals' views. Schizophr Bull 2006; 32(4): 786-94.

[51] Kelly CM, Baker EA, Brownson RC, Schootman M. Translating research into practice: Using concept mapping to determine locally relevant intervention strategies to increase physical activity. Eval Program Plann 2007; 30(3): 282-93

[52] Borden LM, Perkins DF, Villarruel FA, et al. Challenges and opportunities to Latino youth development: Increasing meaningful participation in youth development programs. Hisp J Behav Sci 2006; 28(2): 187-208.

[53] Perkins DF, Borden LM, Villarruel, FA, et al. Participation in structured youth programs: Why ethnic minority urban youth choose to participate--or not to participate. Youth Soc 2007; 38(4): 420-42.

[54] Rosas SR. Concept mapping as a technique for program theory development: An illustration using family support programs. Am J Eval 2005; 26(3): 389-401.

[55] Rosas SR, Camphausen LC. The use of concept mapping for scale development and validation in evaluation. Eval Program Plann 2007; 30(2): 125-35.

[56] Yampolskaya S, Nesman TM, Hernandez M, Koch D. Using concept mapping to develop a logic model and articulate a program theory: A case example. Am J Eval 2004; 25(2): 191-207.

[57] Bimler D, Kirkland J. School truants and truancy motivation sorted out with multidimensional scaling. J Adolesc Res 2001; 16(1): 75102.

[58] Chun J, Springer DW. Stress and coping strategies in runaway youths: An application of concept mapping. Brief Treat Crisis Interv $2005 ; 5(1): 57-74$

[59] Detaille SI, Haafkens J, Hoekstra JB, van Dijk, FJ. What employees with diabetes mellitus need to cope at work: Views of employees and health professionals. Patient Educ Couns 2006; 64(1-3): 183-90.

[60] Bedi RP. Concept mapping the client's perspective on counseling alliance formation. J Couns Psychol 2006; 53(1): 26-35.

[61] Shek D, Tang V, Han X. Evaluation of evaluation studies using qualitative methods in the social work literature (1990-2003): Evidence that constitutes a wake-up call. Res Soc Work Pract 2005; 15 (3): 180-94.

[62] Trochim WM. An introduction to concept mapping for planning and evaluation. Eval Program Plann 1989; 12: 1-16.

[63] Trochim W. The concept system. Ithaca, NY: Author 1987.

[64] MacCallum R. Multidimensional scaling. In: Nesselroade J, Cattell R, Eds. Handbook of multivariate experimental psychology. New York: Plenum 1988; pp. 421-45.

[65] Anderberg MR. Cluster analysis for applications. New York: Academic Press 1973.

[66] Everitt B. Cluster analysis. New York: Halsted Press 1988.

[67] Ward J. Hierarchical grouping to optimize an objective function. J Am Stat Assoc 196; 58: 236-44. 